\title{
AC 2010-1587: IMPROVING ENGINEERING EDUCATION PEDAGOGY VIA DIFFERENTIATED INSTRUCTION
}

\section{John Marshall, University of Southern Maine}

John Marshall received his Ph.D. from Texas A\&M University and is the Internship Coordinator for the Department at the University of Southern Maine. His areas of specialization include Power and Energy Processing, Applied Process Control Engineering, Automation, Fluid Power, and Facility Planning.

\section{William Marshall, Alief Independent School District}

William Marshall is the Director of Instructional Technology and Career \& Technical Education for the Alief Independent School District in Texas. He provides supervision of Program Managers in the areas of Career \& Technical Education, Computer Interventions, Distance Learning, Information Literacy, Technology Applications, Campus Technology Specialists and Library Information Specialists. 


\section{Improving Engineering Education Pedagogy \\ Via Differentiated Instruction}

The participants populating our schools are becoming more diverse. They are coming from different cultures and have different learning styles. They also have different interests and different levels of maturity. As technical teachers, we frequently teach a blend of theoretical and applied engineering topics. Our goal is to provide our students with the skills and knowledge they need to safely and accurately accomplish their jobs to high standards of quality in a cost effective manner.

Central to providing effective instruction is knowing something about how people learn. The more we know about the learning process the more effective we can be in designing and delivering appropriate instruction. A one-size-fits-all teaching method lacks the flexibility needed to challenge and encourage learning in today's effective teaching programs.

"Differentiated instruction, often referred to as universal design, is a teaching and learning style that is the result of neuroscience research on how the human brain processes and retains new information".

\section{Introduction}

"Acknowledging that students learn at different speeds and that they differ in their ability to think abstractly or understand complex ideas is like acknowledging that students at any given age aren't all the same height: It is not a statement of worth, but of reality". ' In a differentiated classroom and laboratory, the teacher proactively plans and carries out varied approaches to content, process, and product in anticipation and response to student differences in readiness, interest, and learning needs. According to Tomlinson, our teaching style "can influence a students' IQ by 20 points in either direction, that's a 40 point IQ swing". 2 Key concepts of differentiated instruction include:

More qualitative than quantitative. Merely assigning more or less work based on a learner's ability is typically ineffective.

Rooted in assessment. Evaluation is no longer predominately something that happens at the end of a chapter to determine "who got it". Assessment routinely takes place to determine the particular needs of individuals.

Student centered. Learning is most effective when experiences are engaging, relevant, and interesting.

A blend of whole-class, group, and individual instruction. 
Research is proving it's a "use it" or "loose it" brain. Activities designed to engage the brain can help grow dendrites, which is the wiring that connects brain cells. The more ways we find to process information the stronger learning (i.e., neural connections between brain cells) becomes. Research is proving that to enhance learning, we should be involving students in lessons by providing a non-threatening environment which allows them time to ask questions, seek solutions, reflect, share thinking about a theme or topic, and respond to other's viewpoints.

In short, as teachers, we need to be able to accomplish learning by doing. Action helps to grow the brain. The real value of subject matter can be heightened for students through activities that combine the classroom instructional context with real-world application. That is, learning can be enhanced even more when academic content is connected to the real world.

Emotions influence learning and memory. Negative emotions impeded learning; positive emotions motivate students to work hard and remember. Emotion affects student attention, which, in turn, influences memory. Current research argues that "intelligence is multidimensional, and that it can be influenced". 3 We're also learning that there are several ways of "knowing." According to Harvard psychologist Howard Gardner, each person has multiple intelligences or ways of knowing. Gardner, for example, sets forth "linguistic intelligence, musical intelligence, logical-mathematical intelligence, spatial intelligence, and bodilykinesthetic intelligence" 3 to name a few. Gardener views intelligence as an individual's ability to solve problems or create products that are valued by society. The implication for teaching and learning is that instructors need to vary the inputs and have a repertoire of strategies for facilitating learning. The more ways we find to process material, the stronger learning becomes. We need to recognize there's no "one best way."

Learning is enhanced in an enriched environment. The physical environment of the classroom is certainly important (aesthetics, climate, etc.), but so too is the learning environment that we create to get students to use their minds well. An enriched learning environment is a setting where students are actively engaged in learning a lesson's key concepts and ideas in depth so the concepts can be transferred to new and novel situations. Students are not passive, merely listening to the "expert" teacher. To create such an environment instructors need to use practices through which students are encouraged to be critical/creative thinkers and where students are taught to draw conclusions, develop arguments, and construct explanations for others about the subject being taught. An enriched learning environment inspires students to collaborate and reflect and develop innovative, unusual, and unique ideas and strategies, that is, to use their minds well.

To speed learning, teachers should continually check for understanding and provide students with thoughtful, timely, and precise feedback. Students need to know how well they are doing and are typically open to suggestions for improvement. Generally, the clearer and more specific an instructor can be with feedback, the better the results for students. Students also benefit from peer reactions and should be encouraged to take responsibility for their own learning (i.e., taught to self-evaluate). Providing accurate feedback and helping students to take charge of learning can stimulate healthy minds. 


\section{Improving Pedagogy with Differentiated Instruction}

A key concept in differentiated instruction is applying a proactive approach to the learning and teaching model. As such, this document is divided into two major themes: active learning; and active teaching.

Topics included in the "Active Learning" section include: 1) Focusing on Learning and Not Teaching; 2) Problem Based Learning; 3) Facilitating Group Learning; 4) Changing Learning Behavior Outside the Classroom; and 5) Preparing to Teach. Topics included in the "Active Teaching" section include: 1) The Seven "Good Practices" for Teachers; 2) Teaching with Hospitality; 3) The Importance of Listening; and 4) Assessment Via the Minute Paper.

The presented pedagogical techniques are not cumbersome or extremely involved. In fact they are fun and very straightforward. Learning more about these practical and helpful methods will make it easier to implement them into your classes. Recall, differentiated instruction is rooted in student centered learning and frequent assessment. Examples and brief case studies are utilized to increase clarity and understanding.

\section{Part One - Active Learning}

\section{Active Learning Technique Number 1 - Focusing on Learning and Not Teaching}

Spence's article, Maybe Teaching is a Bad Idea, suggests that educators should be more focused on the learning process rather than strictly on the teaching process. Too often we follow a primitive but intuitive teaching model such as: "You go to school, a smart person tells you something, and you are expected to learn it and remember it, and if you don't, you are stupid". ${ }^{4}$

According to this model, teaching is telling, and learning is bulimic. Some 70 years of research shows that telling, in the form of lecturing, is just as good for transmitting information as, but "no better than, reading a book, listening to a tape, or watching a film". 4 The same research shows that within weeks and months, students retain only 10 percent of that information. Even then, they can rarely apply it to the messy problems of business and life.

Learning is something students do. It requires compelling problems and well-designed laboratories, studios, workshops, and playing spaces. If we refocus our efforts on learning, professors can exploit information technology to provide data, scholarly references, and simulated problems for cognitive workshops. In those workspaces, student investigators will work side by side with faculty. Together they will learn to create, evaluate, improve, and apply knowledge. Students will learn to be experts and faculty will sharpen their expertise. 


\section{Application of the Theory}

One of Felder's techniques to focus on student learning in a proactive manner is to divide the class into groups of three and supply each group with a handout. The first page of the handout is a brief review of what they should have learned from earlier classes. The next pages include teaching notes with embedded questions that require an understanding and application of the concepts. Felder makes it very clear that in five minutes he will begin calling on specific individuals to answer the questions. ${ }^{5}$

Students realizing that they cannot hide, by not volunteering, take responsibility to actively review and comprehend material that had been presented. Cooperative active learning takes place in each group for the next five minutes. The result of this exercise encourages a common ground of understanding before launching into new material. This simple technique utilized three key aspects of differentiated instruction. Student centered learning, frequent assessment, and a blend of whole-class, group, and individual instruction.

\section{Active Learning Technique Number 2 - Problem Based Learning}

Dutch comments that "the mainstay of traditional teaching is the lecture / listen ritual". 6 Problem based learning, also known as problem solving learning, is as well an old fashion alternative that helps students develop critical skills needed today such as the ability:

- to think critically, analyze and solve complex, real world problems;

- to find, evaluate, and use appropriate learning resources;

- to work cooperatively in teams and small groups;

- to demonstrate effective verbal and written communication skills;

- and to use content knowledge and intellectual skills to become continual learners.

According to Bound \& Feletti, "problem-solving learning is older than formal education itself, namely that learning is initiated by a posed problem, query, or puzzle that the learner wants to solve" ${ }^{7}$ In problem solving learning, complex, real problems motivate students to identify and research concepts and principles they need to know in order to progress through the problems. Students work independently or in small learning teams as they acquire and integrating information in a process that resembles that of inquiry.

Students soon see that "learning is an ongoing process and that there will always be new learning issues to be explored. Because they learn concepts in context, they are more likely to retain that knowledge and apply it appropriately in novel situations".

\section{Application of the Theory}

Problem solving learning through context application is used extensively in courses involving programmable logic controllers. These devices use ladder logic programming involving dozens of instruction sets and function blocks. Students learn the basic attributes of each instruction set and function block, and are then supplied a "machine operating specification". 
“The operating specification details the machine's sequence of operation and identifies requirements such as closed-loop feedback, continuous operation, starting, emergency stopping, and resetting to "home" position". 9

Now students must solve the problem (operating specification) armed with the software tools of instruction sets and function blocks. Once they think they have satisfied the operating specifications, they download their program to the controller and wire in discrete input and output devices. If the system operates in accordance to the specifications, their problem solving effort has succeeded. If not, they note ambiguities and develop a new set of software instructions. "By repeating this design/test/revise process, students develop an analytical thought regime that parallels the traditional "scientific problem solving process". 10

\section{Active Learning Technique Number 3 - Facilitating Group Learning}

Michaelsen feels that small group-based instructional methods can produce a wide variety of positive educational outcomes. These outcomes, however, "only occur when instructors create conditions, which motivate students to prepare for and engage in give-and-take discussions". 11 In these small group-based or also widely referred to as cooperative learning groups, students spend most of their class time working together in teams on activities related to the teaching topic. This approach enables the instructor to listen and monitor students as they work through the material. Price observed that concepts breezed through in 10 minutes in a traditional lecture, were actually taking students an entire class session just to get a feel for. "This powerful teaching technique requires certain premises of teaching and learning to be put into place". 12

\section{Application of the Theory}

This type of interaction can be facilitated by dividing students into small groups of five or six and assigning chapters within the text. These teams of students are then divided into expert groups one through five. After each individual reads the text information, all the "ones" from across all the groups gather for discussion of the material. During these groups students must become the expert of that information. When all major concepts have been addressed and worked through, the student returns to their original group and teaches the information they have acquired. Likewise, all of the other team members complete the same process; all of the "twos" meet, all of the "threes" and so on. The original team after teaching and learning all of the text components from each of the expert groups are tested individually on the material. This facilitation of the group process provides a cooperative foundation for learning where every member is a teacher and a learner, while simultaneously placing the ownership for learning on each individual student.

\section{Active Learning Technique Number 4 - Changing Learning Behavior Outside the Classroom}

Gibbs, in Changing Student Learning Behavior Outside Of Class suggests that teachers identify how many out of class "learning hours" they are entitled to and carefully plan how to make the 
most productive use of all of these hours. "Teachers should establish explicit performance expectations to insure actual participation". 13

\section{Application of the Theory}

One way to increase student participation in learning outside of the traditional classroom is through the incorporation of a web based program such as WebCT or BlackBoard. Teachers can implement involvement strategies in a number of ways. One method is to develop assignments that require an on-line response or chat room discussion. Another method is to require each student to find a hosting firm and develop a case study (relating to the content of the course) that is presented to the class. One more strategy for maximizing outside of class behavior relates to the time consuming activity of viewing audio visual materials such as DVDs. Require the students to view the materials on their own time and write a three paragraph "executive summary" that is collected and serves as discussion points during class.

\section{Active Learning Technique Number 5 - Preparing to Teach}

Doyle in Integrating Learning Strategies into Teaching suggests that we give thought to enhancing student learning, by asking and answering the following seven questions.

"Question \#1 - Prior Knowledge: What background information do my students need to be prepared for my course?

Question \#2 - Levels of Thinking: What cognitive level do my students need to operate at in order to be successful in my course?

Question \#3 - Thinking Skills: What types of thinking skills and strategies do my students need to use to be successful in my course?

Question \#4 - Research Skills: What information gathering skills do my students need to be successful in my course?

Question \#5 - Repair Strategies: What types of fix-up strategies do my students need to be successful in my course?

Question \#6 - Study Skills: What study skills do my students need to be successful in my course? Will they need to organize large amounts of information, summarize information, use rote memory techniques, or prepare for essay exams?

Question \#7 - Learning Strategies: What types of learning strategies do my students need? Will they need to collaborate with others in small or large groups? Will students need to listen, maintain their attention for long periods of time, or take extensive notes". ${ }^{14}$ 


\section{$\underline{\text { Part Two - Active Teaching }}$}

This second section focuses on active teaching ideas and techniques. Topics included are: 1) The Seven "Good Practices" for Teachers; 2) Teaching with Hospitality; 3) The Importance of Listening; and 4) Assessment Via the Minute Paper. Specific applications of the theory are included in many of the active teaching strategies.

As you review these active teaching strategies, notice how well they dovetail into the differentiated instruction blend of whole-class, group, and individual instruction; more qualitative student centered assignments, rather than merely assigning more work; and the importance of routine formal and informal assessment.

\section{Active Teaching Technique Number 1 - Seven “Good Practices” for Teachers}

The following is a brief summary of the Seven Principles for Good Practice in Undergraduate Education as compiled in a study supported by the American Association of Higher Education, the Education Commission of States, and The Johnson Foundation. These Seven Principles are also presented in Arthur W. Chickering and Zelda F. Gamson's book entitled Applying the $\underline{\text { Seven Principles for Good Practice in Undergraduate Education. }}$

\section{Encourage Student / Faculty Contact}

"Frequent student-faculty contact in and out of classes is the most important factor in student motivation and involvement". ${ }^{15}$ Faculty concern helps students get through rough times and keep on working. Knowing a few faculty members well enhances students' intellectual commitment and encourages them to think about their own values and future plans.

\section{Encourage Cooperation Among Students}

"Learning is enhanced when it is more like a team effort than a solo race. Good learning, like good work, is collaborative and social, not competitive and isolated". ${ }^{15}$ Working with others often increases involvement in learning. Sharing one's own ideas and responding to other's reactions improves thinking and deepens understanding.

\section{Encourage Active Learning}

"Learning is not a spectator sport. Students do not learn much just sitting in classes listening to teachers, memorizing pre-packaged assignments and spitting out answers. They must talk about what they are learning, write about it, relate it to past experiences, and apply it to their daily lives. They must make what they learn a part of themselves". 15

\section{Give Prompt Feedback}

"Knowing what you know and don't know focuses learning. Students need appropriate feedback on performance to benefit from courses". ${ }^{15}$ In getting started, students need help in assessing existing knowledge and competence. In classes, students need frequent opportunities 
to perform and receive suggestions for improvement. At various points during classes, and at the end, students need chances to reflect on what they have learned, what they still need to know, and how to assess themselves.

\section{Emphasize Time on Task}

“Time plus energy equals learning. There is no substitute for time on task". ${ }^{15}$ Learning to use one's time well is critical for students and professionals alike. Students need help in learning effective time management. Allocating realistic amounts of time means effective learning for students and effective teaching for faculty. How an institution defines time expectations for students, faculty and administrators, and other professional staff can establish the basis for high performance for all.

\section{Communicate High Expectations}

"Expect more and you will get it. High expectations are important for everyone-- for the poorly prepared, for those unwilling to exert themselves, and for the bright and well motivated". 15 Expecting students to perform well becomes a self-fulfilling prophecy when teachers and institutions hold high expectations of themselves and make extra efforts.

\section{Respect Diverse Talents and Ways of Learning}

At the very center of differentiated instruction is the concept that "there are many roads to learning. People bring different talents and styles of learning to college. Brilliant students in the seminar room may be all thumbs in the lab or art studio. Students rich in hands-on experience may not do so well in theory". ${ }^{15}$ Students need the opportunity to show their talents and learn in ways that work for them. Then they can be pushed to learning in new ways that do not come so easily.

\section{Active Teaching Technique Number 2 - Teaching with Hospitality}

According to Bennett, "we are fortunate that hospitality is practiced more than it is preached. A cardinal academic virtue, hospitality is essential in the classroom as well as in relationships with colleagues". ${ }^{16}$ In the context of engineering education, teaching with hospitality refers to the ability of the professor to provide a nurturing, conducive learning environment. This environment would include listening with respect, receptiveness to other opinions, and requiring the same level of interaction and courtesy from all students.

Although we seldom speak of hospitality as an academic virtue, many of us do practice it. We sense that it is more than a lingering piety, something inherited from the past whose point and purpose is now obscure. In fact, Bennett suggests that hospitality is a cardinal virtue and an essential requirement for what educators are all about. "Without the mutual openness and reciprocity of sharing that are the marks of hospitality, the academy and the classroom become flat and impoverished - reverting to collections or conglomerates of individuals, not communities of learning". 16 
The openness characteristic of hospitality can generate more satisfying teaching and learning. Faithfully practiced, hospitality yields more appreciation for the distinct gifts of the other, whether student or colleague; a greater comfort about the role and burden of being an authority; and more attention to the special responsibility educators have to others, a responsibility often captured by the concept of "trust" and best understood in terms of covenant, not contract.

\section{Active Teaching Technique Number 3 - The Importance of Listening}

According to Carbone, in Listening in the Classroom: A Two-way Street, "pure undistracted listening is one of the greatest gifts we can give each other as human beings. And refusing to listen can be one of the most damaging". ${ }^{17}$ No one can be forced to listen, but listening can be taught. It can be demonstrated through example, and it can be encouraged through the creation of a supportive environment.

Listening to our students has benefits for us too. It can help keep us motivated and inspired and can enliven our teaching. By listening to our students, we can modify the examples and stories we use in lectures to match the cultural changes that take place over the years. This helps keep the material alive for both the teacher and the student.

\section{Active Teaching Technique Number 4 - Assessment Via the Minute Paper}

Researchers have long known that both students and teachers need clear, timely, and according to Price "unambiguous, unbiased feedback on the quality of instruction in order to improve performance". ${ }^{12}$ Classroom Assessment Techniques (CATs) are simple methods faculty use to collect such feedback, early and often, on how well students are learning. Its purpose is to provide faculty and students with information and insights needed to improve teaching effectiveness and learning quality. Faculty use the feedback gleaned through CATs to prompt changes in their teaching. Angelo, in Classroom Assessment: Guidelines for Success, identifies an excellent assessment technique called the "Minute Paper".

"If you've ever wondered, as a class ended, how well your students really understood that day's material, then you understand the impetus behind classroom assessment". ${ }^{18}$ If you've ever been unhappily surprised by students' performance on a midterm, final, or major assignment, then you'll understand the need for classroom assessment. And if you'd like to benefit from lessons learned since 1986, by practitioners and researchers, on how to use classroom assessment to improve teaching and learning, then you may find this technique useful.

In order to improve teaching skills the "Minute Paper" is one of the simplest, most widely used CATs, and a good example of the method. Attributed to Dr. Charles Schwartz, a physics professor at UC Berkeley, "the Minute Paper has been adapted and used since the mid-1980s in virtually every discipline". 19 The Minute Paper asks students to respond anonymously to some variant of these two questions: (1) What are the 2-3 most important things you learned in class today? And (2) What questions remain uppermost in your mind? The "Muddiest Point", a variation on the Minute Paper developed by Professor Frederick Mosteller of Harvard, elicits 
useful feedback with just one question: "What was the muddiest point in today's lecture?" - or in today's discussion, lab, reading, quiz, or other learning activity.

By quickly scanning and summarizing responses to the CAT, the teacher can make welltargeted adjustments to the next class, recognize and capitalize on what students have learned well (or not learned), and clear up questions that might impede further learning. We've learned that classroom assessment is most effective when teachers: (1) explain why they are asking these questions, (2) share a summary of responses with students, and (3) discuss how they and the students can make best use of the feedback. Letting students in on the process helps promote active engagement, participation, and more reflective learning.

At first glance, faculty sometimes confuse CATs with the questions we ask in class, with tests and quizzes, or with familiar teaching techniques. Most teachers ask questions to check understanding. And most of us have noticed that typically only a small, not very representative percentage of students volunteer to answer. CATs, by contrast, elicit anonymous responses, usually in writing, from all or nearly all of the students.

Unlike quizzes and tests, CATs are for quickly assessing the whole group's learning, not for evaluating the work of individual students to assign grades. And while all faculty use teaching techniques, whether they know it or not, some faculty go a step further, using CATs to find out how well those techniques are promoting learning.

\section{Conclusion}

As teachers, we need to be willing to actively probe for what our students don't know and can't do and begin utilizing differentiated techniques to ensure the very best learning experiences for our students. Educators should consider shifting from a teaching centered environment to a differentiated, student center learning paradigm. Learning can and should take place in a variety of venues facilitated by innovative methods of teaching. Central to quality instruction is knowledge of how learning takes place, and the realization that a variety of teaching strategies are needed for diverse learning styles.

\section{Bibliography}

1. Rose, D., and Meyer, A. (2002). Teaching Every Student in the Digital Age: Universal Design for Learning. Association for Supervision and Curriculum Development, Alexandria, Virginia.

2. Tomlinson, C.A., (2001). How to Differentiate Instruction in Mixed-Ability Classrooms. Association for Supervision and Curriculum Development, Alexandria, Virginia.

3. Gardner, H. (1993). Frames of mind: The theory of multiple intelligences, New York, Basic Books.

4. Spense, L. (2000). Maybe Teaching is a Bad Idea. On line: www.teachingexcellence.org downloaded October $12,2000$. 
5. Felder, R., Active Learning with Dr. Richard Felder, downloaded on March 17, 2010 from www.youtube.com/watch?v=1J1URbdisYE.

6. Dutch, B.J., and Allen, D.E., and White, H.B. (1998). Problem-based Learning: Preparing Students to Succeed in the $21^{\text {st }}$ Century. "Essays on Teaching Excellence". Center for Teaching, University of Southern Maine. Vol. 9, No 7, 1997 - 1998.

7. Bound, D. \& Feletti, G. (1991). The Challenge of Problem-Based Learning (p. 13). New York: St. Martin's Press.

8. Albanese, M.A. \& Mitchell, S. (1993). Problem-Based Learning: A Review of Literature on Its Outcomes and Implementation Issues. Academic Medicine, 68. 52-81.

9. Marshall, J. and Marshall, J. (2007). In Search of Teaching Excellence. American Society for Engineering Educators, June, 2007.

10. National Joint Apprenticeship Training Commission (2008), Course 42, International Brotherhood of Electrical Workers.

11. Michaelsen, L., (1998). Three Keys to Using Learning Groups Effectively. "Essays on Teaching Excellence". Center for Teaching, University of Southern Maine. Vol. 9, No 5, 1998.

12. Price, P.C., (2006). Are You as Good A Teacher as You Think? Thought \& Action, Vol. 14, Fall 2006.

13. Gibbs, G., (2001). Changing Student Learning Behavior Outside of Class. "Teaching Excellence". Center for Teaching, University of Southern Maine. Vol. 11, No 1, 1999-2000.

14. Doyle, T., (2008). Helping Students Learn in a Learner-Centered Environmnet: A Guide to Facilitating Learning in Higher Education, Sterling, Virginia: Stylus.

15. Chickering, A.W., and Gamson, Z.F. (1991). Applying the Seven Principles for Good Practice in Undergraduate Education. New Directions for Teaching and Learning. Number 47, Fall 1991. San Francisco: Jossey-Bass Inc.

16. Bennett, J.B., (2001). Teaching With Hospitality. In "Teaching Excellence". Center for Teaching, University of Southern Maine. Vol. 12, No 1, 2000-2001.

17. Clarbone, E. (1999). Listening in the Classroom: A Two-Way Street. "Teaching Excellence". Center for Teaching, University of Southern Maine. Vol. 10, No 4, 1998-1999.

18. Angelo, T.A., (2001). Classroom Assessment: Guidelines for Success. In "Teaching Excellence". Center for Teaching, University of Southern Maine. Vol. 12, No 4, 2000-2001.

19. Thriving in Academe (2008). A Clear Rationale for Lerner-Centered Teaching, NEA Higher Education Advocate. National Education Association. Vol. 26, No. 1, October 2008.

20. Melsa, J. (2005). The "L" Word. Prism, American Society for Engineering Educators, Vol. 14, No 6, Feb. 2005 . 